\title{
Cinema e Violência Contra a Mulher: Contribuições à Formação do Psicólogo Clínico
}

\author{
Tales Vilela Santeiro ${ }^{1}$ \\ Universidade Federal do Triângulo Mineiro, Uberaba, MG, Brasil \\ Joice Veridiane Schumacher \\ Tatiana Machiavelli Carmo Souza \\ Universidade Federal de Goiás, Jataí, GO, Brasil
}

\begin{abstract}
Resumo
Os objetivos da pesquisa foram analisar filmes comerciais/ficcionais sobre Violência Contra a Mulher (VCM), buscando caracterizar encenações desse fenômeno. A seleção dos filmes foi sistemática e realizada em sites especializados no assunto (AdoroCinema, Cinepop etc.), cruzando termos como "violência" e "mulher" $(N=19)$. A análise pressupôs três passos: observação das películas; lançamento de dados observados em planilhas; relação de frequências simples de encenações sobre VCM com aspectos teóricos apontados pela literatura especializada (enfoque quanti-qualitativo). Os agressores eram estranhos $(n=11,39 \%)$, maridos $(n=9,33 \%)$, namorados $(n=4,14 \%)$ e outros $(n=4,14 \%)$. Houve encenações de violência psicológica $(n=19,27 \%)$, física $(n=18,25 \%)$, sexual $(n=16,22 \%)$, moral $(n=12$, $16 \%)$ e patrimonial $(n=7,10 \%)$. As representações fílmicas focaram indícios gerais de traumatização psíquica nas personagens $(n=17,37 \%)$. Os filmes estudados são ilustrativos da realidade das mulheres em contextos de violência; enquanto tais, podem ser convertidos em ferramenta didática ampliadora de debates e reflexões sobre questões de gênero e sobre promoção de saúde em contexto de VCM.
\end{abstract}

Palavras-chave: Psicologia clínica, violência de gênero, filmes, violência intrafamiliar.

\section{Cinema and Violence against Women: Contribution to the Formation of Clinical Psychologist}

\begin{abstract}
The research objectives were analyze business / fictional films about Violence Against Woman (VAW). The selection of films was systematic and carried out in specialized sites on the subject (AdoroCinema, Cinepop etc.), across terms like "violence" and "woman" $(N=19)$. The analysis assumed three steps: observation of motion pictures; data entry observed in spreadsheets; simple frequency ratio concerning VAW scenarios with theoretical aspects pointed out by the literature (quantitative and qualitative approach). The aggressor were strangers $(n=11,39 \%)$, husbands $(n=9,33 \%)$, boyfriends $(\mathrm{n}=4,14 \%)$ and others $(n=4,14 \%)$. There were performances of the following types of violence: psychological $(n$ $=19,27 \%)$, physical $(n=18,25 \%)$, sexual $(n=16,22 \%)$, moral $(n=12,16 \%)$ and patrimonial $(n=7$, $10 \%)$. The filmic representations showed general signs of psychological traumatization in characters $(n$
\end{abstract}

Endereço para correspondência: Universidade Federal do Triângulo Mineiro, Departamento de Psicologia. Avenida Getúlio Guaritá, 159, $3^{\circ}$ andar. Nossa Senhora da Abadia. CEP 38025-440, Uberaba, MG, Brasil. E-mail: talesanteiro@hotmail.com e tatimachiavelli@yahoo.com.br

Financiamento: Programa Institucional de Bolsas da Universidade Federal de Goiás (PIBIC-UFG/ Conselho Nacional de Desenvolvimento Científico e Tecnológico [CNPQ]). 
$=17,37 \%$ ). The studied films are illustrative of the reality of women in situations of violence; as such can be converted to amplifying teaching tool for discussion and reflection on gender issues and on health promotion in the context of VAW.

Keywords: Clinical psychology, gender violence, films, intrafamily violence.

\section{El Cine y la Violencia Contra las Mujeres: Contribución a la Formación de Psicólogo Clínico}

\section{Resumen}

Los objetivos de la investigación fueron analizar las películas de ficción sobre Violencia Contra las Mujeres (VCM), buscando caracterizar escenarios de este fenómeno. La selección de las películas era sistemática y lleva a cabo en los sitios especializados en la materia, a través de términos como "violência" y "mujer" $(N=19)$. El análisis supone tres etapas: la observación de las películas; la entrada de datos observados en las hojas de cálculo; relación de frecuencias simples de las representaciones del VCM con aspectos teóricos señalados por la literatura (enfoque cuantitativo y cualitativo). Los atacantes eran desconocidos (39\%), esposos (33\%), novios (14\%) y otros (14\%). Había un escenario psicológico (27\%), física (25\%), el sexo (22\%), la moral (16\%) y el resto (10\%). Las representaciones fílmicas mostraron signos generales de traumas psicológicos en caracteres (37\%). Las películas estudiadas son ilustrativos de la realidad de las mujeres en situación de violencia; como tal, se puede convertir en la amplificación de herramienta de enseñanza para el debate y la reflexión sobre temas de género y en la promoción de la salud en el contexto de VCM.

Palabras clave: Psicología clínica, violencia de género, películas, violencia intrafamiliar.

O cinema, também conhecido como a Sétima Arte, é um dos grandes adventos do século XIX, criado pelos irmãos Lumière (Bernardet, 2006). No decorrer de sua História, sua linguagem deixou de somente mostrar fatos para contar estórias e, ao fazê-lo, tornou-se altamente sofisticada, porque calcada em elementos semióticos, narrativos, intertextuais e ideológicos (Edgard-Hunt, Marland, \& Rawle, 2013).

O surgimento da Psicologia Clínica, por sua vez, é contemporâneo ao do Cinema; tem suas raízes no modelo médico, no qual cabe ao profissional observar e compreender para posteriormente intervir, isto é, remediar, tratar, curar. Nesse momento inicial, tratava-se de uma prática higienista, estando, por um longo espaço de tempo, distante das questões sociais (Moreira, Romagnoli, \& Neves, 2007), questões essas que se configuram como problemas que atingem a sociedade de forma geral. Assim como a fome, a pobreza, a supressão dos direitos humanos, a violência, e de modo especial, a violência contra a mulher (VCM), objeto deste estudo, passou a ser tratada em filmes comerciais/ficcionais.

Na formação do psicoterapeuta - um desdobramento profissional possível da Psicologia Clínica - existem três referências básicas para o desenvolvimento de um bom profissional, que são: a leitura sobre a teoria e a técnica que irá orientar sua prática, a análise pessoal e a supervisão, onde é possível aprimorar aspectos técnicos das intervenções e aprofundar na discussão clínica dos casos atendidos (Portella, Cortez, \& Carpigiani, 2011).

Nesse contexto, a Sétima Arte pode vir a contribuir como ferramenta na formação de psicólogos clínicos. Ela pode estar integrada ao conhecimento teórico, instigando discussões, ampliando reflexões e elaborações a respeito das experiências que o futuro psicólogo encontrará na sua profissão (Santeiro, 2013).

Tendo em vista o fenômeno da VCM, o Cinema pode servir de instrumento ilustrativo, para o psicólogo em formação, sobre a realidade que ele poderá encontrar na atividade clínica. 
Uma vez que mediada e dialogada, a linguagem dos filmes

. . . seria capaz de desenvolver habilidades clínicas, pois funcionaria como o outro com o qual o psicólogo trabalhará. Um outro que chega e vem marcado por histórias, as quais foram escritas e percebidas a partir das realidades internas e externas, subjetivas e objetivas. (Santeiro, 2013, p. 195)

Nessa direção, a linguagem fílmica reflete práticas e significados sociais, ao mesmo tempo em que os constrói.

\section{Violência Contra a Mulher}

$\mathrm{O}$ fenômeno da VCM tem ganhado espaço na mídia, incluindo-se o Cinema, com cada vez mais frequência (Pinheiro, 2012; Strasburger, Wilson, \& Jordan, 2011). Trata-se de temática relevante para se trabalhar em processos formativos de psicólogos clínicos, tendo em vista sua repercussão e impacto social, cultural e histórico.

$\mathrm{Na}$ atualidade, a VCM tem sido entendida como tópico de saúde pública, multifacetado e multicausal. Por essa natureza, ela tem demandado a criação de leis, de programas e de políticas públicas específicas (por exemplo, Decreto-lei N. $\left.{ }^{\circ} 11.340,2006\right)$ e a consolidação das Delegacias Especializadas de Atendimento à Mulher (DEAM) e das Casas-Abrigo - moradia protegida destinada às mulheres em risco.

Cabe observar que, em contextos nas quais a VCM se presencia, o psicoterapeuta e o psicólogo clínico podem ser elementos importantes no processo de ruptura e de enfrentamento do ciclo da violência (Conselho Federal de Psicologia, 2011). Esses profissionais podem ofertar uma escuta especializada e sigilosa, possibilitando, assim, que a mulher em situação de violência possa compartilhar as experiências vividas que lhe causaram dor. E através dessa escuta possibilitam que elas resgatem a sua condição de sujeito, sua autoestima, suas vontades que ficaram suspensas durante o período em que sofreram violência (Pimentel, 2011).

'Violência contra a mulher' trata-se de termo que deveria ser usado no plural, já que congrega múltiplas expressões e formas de violên- cias, como agressões físicas, sexuais, verbais, (intra)familiares, domésticas, tráficos, dentre outras possibilidades. Ela é perpetrada pelos mais diversos sujeitos e contextos (conhecidos, (ex) parceiros estranhos, instituições públicas e privadas, Estado). De acordo com o artigo $5^{\circ}$ da lei 11.340 (2006), trata-se de “. . . qualquer ação ou omissão baseada no gênero que lhe cause morte, lesão, sofrimento físico, sexual ou psicológico e dano moral ou patrimonial".

A VCM não se resume ao uso da força física, mas a qualquer ameaça de usá-la. Ela está ligada ao poder que um exerce sobre o outro para que esse outro possa realizar suas vontades, seja através do medo ou da força. Ela não se dirige a apenas determinados grupos sociais de mulheres, mas ". . . se configura como umas das formas mais agressivas do patriarcado (expressa no machismo) que é apoiada e consentida . . . pelos aparelhos ideológicos que reproduzem a lógica patriarcal predominante" (Mesquita, 2010, p. 8).

A lei 11.340, em seu artigo $7^{\circ}$, classifica cinco tipos de violência doméstica e familiar contra a mulher (Decreto-lei N. ${ }^{\circ} 11.340,2006$ ):

1. A física, entendida como qualquer conduta que prejudique a integridade física e a saúde;

2. A psicológica que compreende qualquer conduta que cause algum problema emocional, diminuição da autoestima, prejudique o desenvolvimento, limite o direito de ir e vir entre outros;

3. A patrimonial, definida como qualquer comportamento que configure em retenção, subtração ou posse de qualquer objeto ou bens que a pessoa venha a possuir;

4. A sexual que se caracteriza por qualquer conduta que venha a obrigar a pessoa a presenciar ou manter alguma relação sexual sem a sua vontade ou de algum modo a impeça de poder exercitar a sua liberdade em relação a sua sexualidade; e, por fim,

5. A moral, caracterizada por qualquer comportamento que configure em calúnia, injúria ou difamação.

O enfrentamento da VCM não pode estar restrito ao seu combate. Todavia, deve compreender as dimensões da prevenção, da assistência 
e da garantia de direitos às mulheres (Política Nacional de Enfrentamento à Violência contra as Mulheres, 2011). O trabalho do psicólogo clínico pode operar em todas essas dimensões (Hanada, D'Oliveira, \& Schraiber, 2011). Nesse contexto, os serviços que visam o cuidado às mulheres devem ser dirigidos, fundamentalmente, de modo mais amplo e integralizado, envolvendo outros profissionais da saúde mental e das ciências humanas e sociais aplicadas. Isso requer do Estado e dos profissionais, psicólogos ou não, um enfoque intersetorial e multidimensional, capaz de provocar mudanças culturais, educativas e sociais (Política Nacional de Enfrentamento à Violência contra as Mulheres, 2011).

De acordo com Waiselfisz (2015), 85,9 mil meninas e mulheres em situação de violência cometida por familiar ou pessoa com vínculo íntimo de afeto foram atendidas pelo Sistema Único de Saúde, no Brasil, apenas no ano de 2014. Diante desses dados, reafirma-se a importância de estudos que deem visibilidade ao fenômeno da VCM. Além dessas questões, mulheres em situação de violência possivelmente estarão dentre pacientes que o psicólogo encontrará na prática clínica.

\section{Considerações sobre Violência e VCM na Ótica Psicanalítica}

Apoiando-se na teoria psicanalítica, pode-se dizer que o termo violência é aplicado em tão variados contextos que isso torna a sua compreensão problemática. $\mathrm{O}$ ser humano é tentado a todo o momento a satisfazer a necessidade que é posta por pulsões agressivas: satisfazê-las a custo de seu próximo, explorando seu trabalho, tomando suas posses sem o seu consentimento, utilizando-o sexualmente sem sua permissão, causando-lhe sofrimento, agredindo-lhe, trazendo dor, torturando, matando (Vieira, 2013).

A violência configura-se em um ataque ao sujeito violentado e costuma trazer como consequência efeitos desastrosos à sua subjetividade (Fiorini, 2008). Cabe, assim, falar do conceito de trauma psíquico para elucidar o fenômeno da VCM. Freud (1920/1996) descreve o trauma como uma dor que não pode ser representada psiquicamente e essa falta de representação traz um grande impacto no processo de subjetivação da pessoa. Uma experiência vai ser tomada como traumática quando a angústia e a dor atingem um ponto insuportável, que vão proporcionar ao sujeito uma sensação de quebra do eu.

Sob o efeito do trauma aparece o mecanismo de compulsão à repetição, no qual o acontecimento perturbador, aflitivo, retorna de forma repetitiva, porém de modo elaborado pelo psiquismo. Esse aparato se configura na ação de certos sujeitos em repetir acontecimentos passados, situações aflitivas durante suas vidas, sem reconhecer sua própria participação em ocasionar tais incidentes ou em relacionar as situações atuais com experiências passadas (Paim, 2010).

No mecanismo de compulsão à repetição a pessoa é obrigada a repetir o material reprimido como se fosse uma experiência nova, em vez de recordá-lo como algo pertencente ao passado (Freud, 1920/1996). O que se repete são, em sua maioria, experiências infantis que trouxeram sofrimento, principalmente aquelas relacionadas a perdas inerentes à vida. Essas experiências "retornam" subentendidas de várias maneiras (Barbosa, 2010), como se o sujeito permanecesse em estado de "busca" de elaboração do que não pudera ser compreendido emocionalmente, quando da experiência da situação traumática propriamente dita.

Os traumas vividos na infância vão encontrar lugar na vida adulta para se manifestar; pessoas que passaram por situações de maus tratos no passado podem revivê-las no presente sem ter consciência dessa repetição (Lima \& Werlang, 2011). Por essa via, acredita-se que mulheres que possuem casos de violência em suas histórias, ou na de sua família, podem vir a reviver inconscientemente esses episódios, quando adultas. Nessas situações, a mulher reedita experiências infantis, pelo caminho de dificuldades já conhecidas, repetindo a problemática.

Considerando esse apanhado introdutório, nesse estudo objetivou-se realizar levantamento de filmes comerciais que tratem do tema VCM, assim como verificar a existência de relação entre os casos de VCM retratados com aspectos enfocados pela literatura especializada. 


\section{Método}

A pesquisa de títulos foi realizada em sites especializados em Cinema, considerando os resultados ranqueados em primeiro lugar dispostos pela ferramenta Google: AdoroCinema, Cine Pop, Omelete, e-pipoca, Cinema 10 e Netflix. Em cada um dos sites citados, a busca de filmes considerou os seguintes vocábulos: "violência", "abuso", "menina", "mãe" e "mulher".

Os seguintes critérios foram adotados para a inclusão dos títulos na amostra: (a) ano das produções entre 2005 e 2014; e (b) idioma ou legendagem em português; (c) disponibilidade para assistência em DVD, em videolocadoras ou nos sites em que as buscas foram realizadas; e (d) a encenação de VCM, por meio de imagens e/ou de diálogos, como tema central (representações encenadas por protagonistas, ou cuja extensão de cenas era longa em relação ao tempo total da obra, isto é, não eram esporádicas) ou secundário (representações encenadas por coadjuvantes, ou cuja extensão de cenas era breve em relação ao tempo total da obra, ou seja, eram esporádicas).

A primeira busca de filmes resultou em 20 títulos, dos quais um não atendeu aos critérios preestabelecidos e foi excluído da amostra, por ser um documentário: Canto de cicatriz. Aparentemente os mecanismos de busca fílmicos o incluíram por ele também versar sobre a VCM. Dentre os 19 filmes selecionados, dois foram escolhidos aleatoriamente para realização de estudos piloto (Um lugar para recomeçar e Desejo de liberdade).

Com base nos estudos piloto e nos pontos centrais sobre VCM apontados na literatura especializada, uma ficha para registro de observações foi desenvolvida. Para preenchimento desta, os filmes foram assistidos plano a plano, com especial atenção às seguintes questões, que foram observadas de modo sistemático em cada um deles: (a) Qual o gênero (drama, comédia, terror, suspense etc.) e a nacionalidade do filme?; (b) Situações de VCM são retratadas de modo central ou secundário, nos argumentos dos filmes?; (c) Quais os contextos em que ocorrem VCM (institucionais [familiar, escolar, religiosos etc.] e não institucionais [ruas, praças, par- ques etc.])?; (d) Qual o perfil das mulheres em situação de violência e dos agressores (idade, grau de proximidade, possuía ou não trabalho, possuía filhos, estado civil)?; (e) Qual(is) tipo(s) de VCM (sexual, física, psicológica, patrimonial e moral) é(são) retratada(os)?; (f) Quais as implicações que $o$ ato de violência ocasionava para a mulher? Considerando que entre as implicações retratadas pode-se ter a traumatização psíquica, a vítima apresentava algum sintoma dela? Se sim, qual(is)? $\mathrm{O}(\mathrm{s})$ sintoma(s) era(m) apresentado(s) anteriormente e/ou posteriormente ao ato de violência?; (g) A personagem vitimizada se lançava em situações repetitivas de violência (compulsão à repetição)?

Após o lançamento dos dados observados nas fichas, o tratamento deles considerou as frequências brutas e relativas de ocorrência de encenações e de demais características fílmicas pertinentes aos objetivos do estudo (análise quantitativa). Após esses cálculos, procurou-se relacionar esses resultados com aspectos enfocados pela literatura especializada sobre VCM, com ênfase naquela orientada psicanaliticamente, nos casos em que isso foi viável (análise qualitativa).

\section{Resultados e Discussão}

Com relação à categoria gênero das películas, algumas delas apresentavam gêneros sobrepostos e cada um deles foi considerado de modo independente $(N=24)$. Essa categorização foi estabelecida a partir das informações colhidas nos sites especializados no assunto (AdoroCine$m a$, Cinepop etc.) e contemplou: drama ( $n=17$; $71 \%)$, suspense $(n=4 ; 17 \%)$, ação, cinebiografia e policial ( $n=1 ; 4 \%$ cada).

A constância do gênero dramático apresenta relação com a temática abordada, levando em conta que os aspectos emocionais das mulheres que sofrem violência, assim como das pessoas que direta ou indiretamente estão envolvidas, podem ser entendidos ou considerados como, de fato, dramáticos, na acepção do que há de comovente nas encenações. O filme Millenium: Os homens que não amavam as mulheres (Fincher, 2011), é exemplificador dessa questão, já 
que a VCM foi trabalhada de maneira tão enfática que gera no espectador sentimentos de compaixão, tristeza e asco, requerendo dele condições emocionais para lidar com as informações que eram encenadas, algo semelhante ao relatado por Santeiro e Rossato (2013), quando estudaram representações de abusos sexuais infantis e adolescentes em filmes comerciais.
Sobre a nacionalidade das produções, 9 (49\%) eram estadunidenses, 3 (16\%) brasileiras, 2 (10\%) coproduções multinacionais, 1 britânica, 1 espanhola, 1 francesa, 1 grega e 1 egípcia ( $5 \%$ cada). Por se tratar de um fenômeno universal, que abarca variadas culturas, independentemente do nível de desenvolvimento econômico, a VCM tem sido retratada nos filmes de diversos países (Leal, 2010; Santos \& Vieira, 2011).

\begin{tabular}{|c|c|c|c|}
\hline Título & Diretor, ano de produção & Gênero & País \\
\hline Antônia & Tata Amaral, 2006 & Drama & Brasil \\
\hline Cairo $678^{*}$ & Mohamed Diab, 2010 & Drama & Egito \\
\hline Cidade do silêncio* & Gregory Nava, 2006 & Suspense / Drama / Policial & EUA \\
\hline Desejo de liberdade* & Jag Mundhra, 2006 & Drama & Reino Unido/Índia \\
\hline Elisa $K{ }^{*}$ & Judith Colell, 2010 & Drama & Espanha \\
\hline $\begin{array}{l}\text { Lado a lado com um assas- } \\
\text { sino* }\end{array}$ & Danny Lerner, 2009 & Ação / Drama & EUA/Israel/França \\
\hline Lovelace & $\begin{array}{l}\text { Rob Epstein, Jeffrey Friedman, } \\
2013\end{array}$ & Cinebiografia / Drama & EUA \\
\hline $\begin{array}{l}\text { Millenium: Os homens que } \\
\text { não amavam as mulheres }\end{array}$ & David Fincher, 2011 & Drama / Suspense & EUA \\
\hline Miss Violence* & Alexander Avranas, 2013 & Drama & Grécia \\
\hline Mulheres do Brasil & Malu de Martino, 2006 & Drama & Brasil \\
\hline $\begin{array}{c}\text { Preciosa: Uma história de } \\
\text { esperança* }\end{array}$ & Lee Daniels, 2009 & Drama & EUA \\
\hline Prenda-me* & Jean-Paul Lilienfeld, 2012 & Suspense & França \\
\hline Sob o domínio do medo & Rod Lurie, 2011 & Suspense & EUA \\
\hline Sonhos roubados & Sandra Werneck, 2009 & Drama & Brasil \\
\hline Tabu & Alan Ball, 2007 & Drama & EUA \\
\hline Terra fria* & Niki Caro, 2005 & Drama & EUA \\
\hline Tiranossauro* & Paddy Considine, 2011 & Drama & Reino Unido \\
\hline Um lugar para recomeçar & Lasse Hallström, 2005 & Drama & EUA/Alemanha \\
\hline Um porto seguro* & Lasse Hallström, 2013 & Romance / Drama & EUA \\
\hline
\end{tabular}

Figura 1. Relação de títulos em português brasileiro, direção, ano, gênero e nacionalidade da produção. Nota. Asteriscos após o título indicam obras que apresentam a VCM como tema central de seus enredos.

A VCM foi enfocada como tema central em 11 (58\%) longas e como secundário em oito (42\%). Em Prenda-me (Lilienfeld, 2012) ela foi apresentada como tema central; nele há representações dos diversos tipos de violência (física, sexual, psicológica, patrimonial e moral), assim como foram mostradas implicações dos atos de violência para a vítima. Entre essas implicações, é vista de forma clara a traumatização psíquica pela qual Gaston (vítima) passa devido à vio- 
lência que sofre, e também o ciclo de repetitivas situações de violência em que essa personagem se lança (compulsão à repetição). Um lugar para recomeçar (Hallström, 2005) é um exemplo que trata da VCM de forma secundária, em meio ao tema de recomeço e conflitos familiares vividos pelos protagonistas.

Quando se investigou os contextos em que a VCM ocorria, verificaram-se, na amostra estudada, 26 episódios de violência ${ }^{2}$ que se efetivaram em quatro contextos: no âmbito familiar $(n=15$; $58 \%)$, no público [ruas, parques, praças etc.] $(n=$ $6 ; 23 \%)$, no laboral $(n=4 ; 15 \%)$ e no escolar $(n$ $=1 ; 4 \%$ ). Como demonstrado pelos dados fílmicos, a VCM atinge várias conjunções e abarca a maioria dos contextos em que as mulheres estão inseridas. Essa modalidade de violência é uma das mais vigorosas expressões do patriarcado, sendo apoiada e cometida cotidianamente pela mídia, pela escola, pelas instituições religiosas, pela família e pelos diversos aparelhos ideológicos $^{3}$ existentes que reproduzem essa lógica (Mesquita, 2010).

O contexto familiar/residencial foi o que mais apareceu nas cenas de violência nas películas, representando $58 \%$ da amostra, dado semelhante aos observados em pesquisas não fílmicas realizadas por Mesquita (2010) e Madureira et al. (2014), que relatam a maioria dos episódios de violência ocorrerem no contexto familiar, sendo esse ambiente mais privado e aonde os agressores se localizam mais frequentemente (cônjuges, pais, mães e outros.), em especial os cônjuges. Assim, percebe-se uma face perversa do ambiente familiar, que historicamente é constituído como um local acolhedor e de segurança, e que, porém pode se converter em espaço de conflito e de violência (Mesquita, 2010).

$2 \mathrm{O} N$ inflacionou porque alguns filmes retratavam mais de um episódio. Esse fenômeno relativo ao inflacionar da amostra se repetirá doravante, em outras análises.

3 Aparelhos ideológicos são as diversas instituições responsáveis por estabelecer o controle da sociedade, como a igreja, a educação, a política, a justiça entre outros; a ação promovida através desses aparelhos explica a presença da VCM em vários contextos, pois os mesmos permeiam a sociedade como um todo.
Quando se analisou a faixa etária das mulheres em situação de violência, percebeu-se em 25 encenações que eram adultas $(n=16 ; 64 \%)$, adolescentes $(n=8 ; 32 \%)$ e crianças $(n=1 ; 4 \%)$. Esses dados novamente se assemelham aos observados na pesquisa de Mesquita (2010) e também aos encontrados por Labronici, Ferraz, Trigueiro e Fegadoli (2010) e por Madureira et al. (2014), que indicaram maior incidência da VCM na fase adulta.

No filme Miss Violence (Avranas, 2013), observou-se a ocorrência da VCM na infância, nele a criança sofre agressões juntamente com a mãe e as irmãs adolescentes. Pode-se reafirmar que o conceito de VCM é amplo e abarca todas as fases do ciclo vital da mulher, tal como contemplado na Política Nacional de Enfrentamento à Violência contra as Mulheres (Política Nacional de Enfrentamento à Violência contra as $\mathrm{Mu}$ lheres, 2011). Também se acredita ser oportuno salientar que é recente o movimento histórico de considerar que a violência contra crianças não é algo "natural" e simplesmente permitido como decorrência de questões de "educação dos filhos", em diversas culturas (no caso de Miss Violence, a produção é grega).

$\mathrm{Na}$ amostra, 25 encenações apresentaram o estado civil das mulheres em contexto de violência como: casadas $(n=11,44 \%)$, solteiras $(n=9$, $36 \%)$ e amasiadas $(n=5,20 \%)$. A literatura revela que a maior parte das mulheres é violentada pelos seus (ex) companheiros. Esse tipo de observação evidencia os riscos psíquicos e físicos que essas mulheres correm, pois em grande parte dos casos elas são expostas à violência dentro do lar e o agressor é uma pessoa do seu convívio, com a qual possui um envolvimento emocional (Griebler \& Borges, 2013; Labronici et al., 2010; Lima \& Silva, 2012; Waiselfisz, 2015).

Ao analisar a faixa etária dos agressores, percebeu-se em 24 representações que eram adultos $(n=22,92 \%)$ e adolescentes $(n=2,8 \%)$. Os dados a respeito da faixa etária corroboram os das referências pesquisadas, que apontam a maioria dos agressores pertencentes à fase adulta (Griebler \& Borges, 2013; Madureira et al., 2014; Silva, Gomes, Acosta, Barlem, \& Fonseca, 2013). Nas 24 encenações, o estado civil 
dos agressores apresentou-se como: casado ( $n=$ $13,54 \%)$, solteiro $(n=5,21 \%)$ e amasiado ( $n$ $=6,25 \%$ ), de modo semelhante aos resultados relatados por Madureira et al. (2014), obtidos em contexto não fílmico.

No que tange a relação com o agressor, os seguintes dados foram verificados: ausência de vínculo afetivo $(n=10,37 \%)$, esposa $(n=$ $7,26 \%)$, namorada, ex-namorada e filha $(n=3$, $11 \%$ cada), e sobrinha $(n=1,4 \%)$. Relacionando esses dados com os obtidos nos estudos de Lima e Silva (2012), Mesquita (2010) e Silva et al. (2013), é possível dizer que há correspondência no que diz respeito à maioria das mulheres em situação de violência serem (ex)esposas e (ex)namoradas. Contudo, o dado ressaltado nos filmes, de que $37 \%$ dos casos de violência são perpetrados por agressores que não possuem nenhum vínculo afetivo com a vítima, contradiz aqueles demonstrados em outras pesquisas estudadas (não fílmicas), sendo o estudo de Madureira et al. (2014) um exemplar que retrata essa contradição. Tem-se, como exemplo de filme onde a violência foi cometida por agressores que não possuem nenhum vínculo de afeto com a vítima, Cairo 678 (Diab, 2010), uma produção egípcia que trata das agressões sofridas por mulheres em diversos ambientes públicos, por pessoas desconhecidas, problematizando a dificuldade da mulher em denunciar e admitir que está em situação de violência, no Egito (país da produção).

Quanto aos tipos de violência cometidos contra a mulher, verificou-se 72 episódios no total, subdivididos nas seguintes categorias: psicológica $(n=19,26 \%)$, física $(n=18,25 \%)$, sexual $(n=16,22 \%)$, moral $(n=12,17 \%)$ e patrimonial $(n=7,10 \%)$. Apesar dos tipos terem sido separados para fins de análise, nos títulos analisados eles se apresentaram sempre combinados entre si. Em alguns ocorreu de aparecer todos os tipos de violência, como é o caso de Preciosa: Uma história de esperança (Daniels, 2009). Nele a protagonista, uma jovem de 16 anos, sofre desde violência sexual por parte do pai, até psicológica, moral, física e patrimonial por parte da mãe.

Estudos como os de Griebler e Borges (2013), de Labronici et al. (2010), de Lima e Silva (2012) e de Madureira et al. (2014), apontam, assim como observado nas películas, para uma maior incidência da violência psicológica e física, embora não raro acompanhadas dos demais tipos. Observa-se que a psicodinâmica familiar do filme de Daniels (2009) foi objeto de estudo de Santeiro, Rossato, Juiz e Gobbetti (2014).

Ponderando sobre o forte impacto causado pela violência na vida das mulheres, a superação desse estado envolve diferentes segmentos sociais, exigindo diversos olhares e modalidades de intervenção, entre elas a do psicólogo clínico (Conselho Federal de Psicologia, 2011). Referindo-se ao atendimento psicológico a mulheres em situação de violência, é necessário dizer que o psicólogo necessita ter um embasamento teórico-clínico, e também social. Como o atendimento a esse segmento normalmente não ocorre em settings clínicos tradicionais, tem-se que considerar o conceito de clínica ampliada, que proporciona a expansão das diversas formas de atuação do psicólogo clínico, adaptando a prática clínica aos diversos espaços em que ela se faz necessária (Monteiro, 2012). O psicólogo pode, assim, ampliar o alcance do trabalho clínico às mulheres em situação de violência, pois esse tipo de modelo considera parceria com outros setores, como a Justiça, a segurança pública e a assistência social

Em alusão às implicações que o ato de violência pode ocasionar para a mulher, observaram-se 46 encenações classificadas da seguinte forma: traumatização psíquica $(n=17,37 \%)$, afastamento da família/amigos e baixa autoestima $(n=7,15 \%$ cada), saída/abandono do lar $(n=$ $6,13 \%)$, perda do emprego $(n=3,7 \%)$, gravidez e morte ( $n=2,4 \%$ cada) e fim do relacionamento e suicídio ( $n=1,2 \%$ cada). A repercussão e as implicações da violência podem ser sentidas nas saúdes física e mental, e no campo social onde a mulher está inserida, de modo indissociado (Madureira et al., 2014; Paiva, Santos, \& Santos, 2014). Aqui elas são tratadas em separado tão-somente por razões didáticas.

Como exemplo de uma implicação física do ato de violência pode-se destacar Preciosa: Uma história de esperança (Daniels, 2009), no qual a protagonista tem duas gestações indesejadas e contrai o vírus do HIV, como consequências 
das violências sofridas. Prenda-me (Lilienfeld, 2012) exemplifica implicações no âmbito da saúde mental da mulher; nele a protagonista, após ser agredida, desenvolve síndrome do pânico, que a impossibilita de levar uma vida habitual. Em Terra fria (Caro, 2005) observa-se um modelo de violência que causa implicações no âmbito social da vida da mulher, que seria a perda do emprego e o afastamento da família e dos amigos.

Para compreender o que se passa física e emocionalmente com as mulheres que sofrem violência, é necessário voltar o olhar para o sujeito, para o ser humano que teve toda sua vida atingida por meio da violência (Paiva et al., 2014). Esse olhar especializado pode ser prestado pelo psicólogo clínico, que neste contexto pode integrar o processo de enfrentamento do ciclo de violência, buscando preveni-lo, tratá-lo e promover saúde.

Pensando especificamente na traumatização psíquica, verificou-se que em 17 (85\%) obras as mulheres em situação de violência apresentaram algum sintoma ou um conjunto deles, posteriormente ao ato de violência propriamente dito. É válido considerar que a traumatização psíquica duela com as tentativas de elaboração e inscrição psíquica, quando a dor e a angústia atingem um limiar considerado intolerável é que vai surgir na pessoa a sensação de quebra do eu, acompanhada de vários outros sintomas (Freud, 1920/1996). O ato de violência representa, assim, um marco: é por meio dele que indícios de traumatização podem ser observados na vida concreta e psíquica das mulheres vitimizadas.

Ao analisar os sintomas apresentados pelas personagens violentadas, 37 encenações deles foram encontradas. Eles foram classificados em: estresse pós-traumático $(n=15,41 \%)$, ansiedade $(n=7,20 \%)$, depressão, delírios e alucinações ( $n=5,13 \%$ cada um). Como dito anteriormente, Freud (1920/1996) descreveu o trauma como uma dor que não pode ser representada psiquicamente e essa falta de representação traz um grande impacto no processo de subjetivação humana.

O trauma retrata uma dor que é irrepresentável e não é admirável que tamanha dor causasse o desenvolvimento de conflitos e sintomas psicológicos como os encontrados nas personagens das produções estudadas. Assim, nelas os sintomas não apareceram isoladamente um do outro e a mulher que se encontrava em situação de violência apresentava mais de um dos sintomas levantados, como pode ser visualizado em filmes como: Preciosa: Uma história de esperança (Daniels, 2009), Prenda-me (Lilienfeld, 2012), Elisa K. (Colell, 2010) e Desejo de liberdade (Mundhra, 2006).

No que diz respeito à compulsão à repetição, em 11 (58\%) obras as personagens em situação de violência se colocaram em condições repetitivas de violência, em contraposição às 8 $(42 \%)$ restantes. Cabe lembrar que o mecanismo de compulsão à repetição surge a partir do efeito do trauma, numa complexa dinâmica psíquica, onde os acontecimentos aflitivos e perturbadores "retornam", configurando a ação de certos sujeitos em repetir fatos penosos durante suas vidas, sem reconhecer sua própria participação em ocasionar tais incidentes, ou em relacionar os mesmos com situações passadas (Paim, 2010).

Uma questão específica da compulsão à repetição é o fato de se reiterar, de diferentes modos, o fato angustiante em questão, porém isso ocorre sem nenhuma consciência de se estar repetindo um conteúdo similar (Freud, 1920/1996). Prenda-me (Lilienfeld, 2012) ilustra o protótipo de relação onde aparece o mecanismo de compulsão à repetição. Gaston - a protagonista - narra a sua história, na qual aparece histórico de violência na família. O pai agredia a mãe e ela presenciava esses conflitos, no passado infantil. Nas relações atuais Gaston revive essas situações de violência intrafamiliar. Ela trilha, assim, caminhos semelhantes de dificuldades sofridas pela mãe, tal como sugere Barbosa (2010).

É percebido, assim, que as mulheres dos filmes analisados se lançam em situações repetitivas de violência também porque apresentam um histórico de violência anterior. A partir deste, elas parecem tender a repetir inconscientemente percursos que lhes são de algum modo "familiares", algo como se indagassem a si mesmas: "minha mãe era assim, maltratada pelo meu pai, então assim serei nas minhas relações com homens". Isto é, a composição da família interna 
delas estaria permeada pela violência como uma linguagem possível.

Os filmes nos quais as mulheres não apresentavam o mecanismo de compulsão à repetição eram os mesmos em que o tema da violência era enfocado de maneira periférica, como por exemplo: Um lugar para recomeçar (Hallström, 2005), Antônia (Amaral, 2006) e Sob o domínio do medo (Lurie, 2011). Desse modo, essa característica leva à constatação de que, por não ser o tema principal dos filmes e, portanto, por não haver diversidade e profundidade de encenações, não foi possível observar esse tipo de aspecto nas histórias das respectivas personagens.

\section{Considerações Finais}

Os filmes estudados trazem encenações de temáticas e características dos envolvidos em situações de VCM, semelhantes às enfocadas na literatura especializada, no que se referem a contextos, perfis das mulheres em situação de violência e a ocorrência de traumatização psíquica. Eles permitem, assim, realizar aproximações entre as realidades fílmicas e factuais.

Essa aproximação dos filmes com a realidade não tem a pretensão de substituir o estudo das teorias e muito menos de realizar uma transposição exata de um tipo de experiência para a outra, mas sim de servir como mais uma ferramenta no processo de formação de psicólogos clínicos. Deste modo, com este trabalho procurou-se ressaltar a linguagem dos filmes como disparador de discussões e provocador de conhecimentos que vão além dos possíveis de serem obtidos de modo racional, na academia.

A partir disso pode se considerar que os filmes que aqui enfocaram o tema da VCM podem ser instrumentos neste processo de formação, levando o estudante de Psicologia a se deparar com situações semelhantes às que serão encontradas em ambientes de trabalho "reais", assim como experimentar de nuances dos sentimentos que essas situações humanas podem provocar. É necessário que, neste contexto, o psicólogo clínico possua disponibilidade emocional, caracterizada pela capacidade de desenvolver e exercer a empatia, pois as mulheres que se encontram em situação de violência não podem ficar à mercê de outro tipo de violência, ao serem escutadas: a indiferença frente ao relato do seu sofrimento.

É responsabilidade dos profissionais que atuam nesta área ajudar a resgatar a autonomia das mulheres, muitas vezes perdida frente às experiências traumatizantes. Afinal, cabe lembrar que o enfrentamento da VCM deve compreender as dimensões da prevenção, da assistência e da garantia de direitos às mulheres (Política Nacional de Enfrentamento à Violência contra as Mulheres, 2011). Em complemento à necessária atenção que precisa ser dada à mulher em situação de violência, cabe ressaltar, ainda, que nos dias de hoje o agressor também deve estar no foco de atenção de trabalhos oferecidos pelo clínico e por outros profissionais que integram as situações de enfrentamento à VCM. O entendimento da VCM como um fenômeno complexo, historicamente constituído e multicausal deve ser considerado com seriedade, mesmo quando se pretende estudar suas manifestações em obras fílmicas.

É sabido da existência de outros filmes que abordam a VCM e que a busca efetuada não os selecionou, conforme limites metodológicos do estudo. Contudo, a partir dos aqui considerados foi possível compreender vários de seus aspectos e acentuar aos interessados no assunto, algumas implicações para processos de formação de psicólogos clínicos.

Outra limitação do estudo tem respaldo no enfoque dispensado ao tratamento de dados. As análises correspondentes visaram à compreensão do conjunto das obras, fazendo com que temas altamente complexos pudessem ser apenas brevemente discutidos e fundamentados teoricamente. Esse tipo de restrição pode ser superado ao se eleger, em empreitas futuras, algum título como estudo de caso, tal como pode ser verificado em contribuições como as de Pinheiro (2012) e de Santeiro et al. (2014).

O Cinema, enfim, pode vir a ser usado como um instrumento ilustrativo da VCM para o psicólogo em formação, ao retratar situações correspondentes às que serão encontradas na realidade de seu trabalho, ainda que por meio da linguagem artística. Ele pode servir para intro- 
dução ao estudo de temas polêmicos e de difícil abordagem, assim como para temas corriqueiros no processo de ensino-aprendizagem, tornando-se um recurso adicional no processo de formação de psicólogos clínicos (Santeiro, 2013). Nessa direção, ele pode ser uma ferramenta didática profícua, fomentadora e ampliadora de debates a respeito das questões de gênero e de promoção de saúde no campo de estudos da VCM.

\section{Referências}

Amaral, T. (Dir.). (2006). Antônia [Filme]. Brasil. Cor. $90 \mathrm{~min}$.

Avranas, A. (Dir.). (2013). Miss Violence [Filme]. Grécia. Cor. 98 min. Legendado.

Ball, A. (Dir.). (2007). Towelhead/Tabu [Filme]. Estados Unidos. Cor. 124 min. Legendado.

Barbosa, E., Neto. (2010). O conceito de repetição na psicanálise freudiana: Ressonâncias clínicas na reelaboração simbólica do repetido (Dissertação de mestrado em Psicologia Clínica, Universidade Católica de Pernambuco, Recife, PE, Brasil). Recuperada em http://www.unicap.br/tede//tde busca/arquivo.php? $\operatorname{cod}$ Arquivo $=302$

Bernardet, J. C. (2006). O que é cinema. São Paulo, SP: Brasiliense.

Caro, N. (Dir.). (2005). North Country/ Terra fria [Filme]. Estados Unidos. Cor. $126 \mathrm{~min}$. Legendado.

Colell, J. (Dir.). (2010). Elisa K [Filme]. Espanha. Cor. $71 \mathrm{~min}$. Legendado.

Considine, P. (Dir.). (2011). Tyrannosaur/ Tiranossauro [Filme]. Reino Unido. Cor. 92 min. Legendado.

Conselho Federal de Psicologia. (2011). Documento de referência para atuação dos psicólogos em serviços de atenção a mulher em situação de violência. Recuperado em http://www.crprj.org. br/documentos/2012-doc_mulheres.pdf

Daniels, L. (Dir.). (2009). Precious/Preciosa: Uma história de esperança [Filme]. Estados Unidos. Cor. 110 min. Legendado.

Decreto-lei N. ${ }^{\circ} 11.340$, de 7 de agosto de 2006. (2006). Cria mecanismos para coibir a violência doméstica e familiar contra a mulher. Brasília, DF: Presidência da República, Casa Civil, Subchefia para Assuntos Jurídicos. Recuperado em http://www.planalto.gov.br/ccivil_03/ ato20042006/2006/lei/111340.htm

Diab, M. (Dir.). (2010). 678/Cairo 678 [Filme]. Egito. Cor. $100 \mathrm{~min}$. Legendado.

Edgard-Hunt, R., Marland, J., \& Rawle, S. (2013). A linguagem do Cinema. Porto Alegre, RS: Bookman.

Epstein, R. (Dir.), \& Friedman, J. (Dir.). (2013). Lovelace [Filme]. Estados Unidos. Cor. 93 min. Legendado.

Fincher, D. (Dir.). (2011). The girl with the dragon tattoo/Milllenium: Os homens que não amavam as mulheres [Filme]. Estados Unidos. Cor. 158 min. Legendado.

Fiorini, L. G. (2008). Los laberintos de la violência. Buenos Aires: Asociación Psicoanalítica Argentina.

Freud, S. (1996). Além do princípio de prazer. In S. Freud, Edição standard brasileira das obras psicológicas completas de Sigmund Freud (Vol. 18, pp.11-75). Rio de Janeiro, RJ: Imago. (Original publicado em 1920)

Griebler, C. N., \& Borges, J. L. (2013). Violência contra a mulher: Perfil dos envolvidos em boletins de ocorrência da Lei Maria da Penha. Psico, 44(2), 215-225. Recuperado em http://revistaseletronicas.pucrs.br/ojs/index.php/revistapsico/ article/view/11463/9640

Hallström, L. (Dir.). (2005). An unfinshed live/Um Lugar para Recomeçar [Filme]. Estados Unidos; Alemanha. Cor. 101 min. Legendado.

Hallström, L. (Dir.). (2013). Safe Haven/Um porto seguro [Filme]. Estados Unidos. Cor. $116 \mathrm{~min}$. Legendado.

Hanada, H., D’Oliveira, A. F. P. L., \& Schraiber, L. B (2011). Os psicólogos na rede de assistência a mulheres em situação de violência. Estudos $\mathrm{Fe}$ ministas, 18(1), 33-59.

Labronici, L. M., Ferraz, M. I. R., Trigueiro, T. H., \& Fegadoli, D. (2010). Perfil da violência contra mulheres atendidas na Pousada de Maria. Revista da Escola de Enfermagem da USP, 44(1), 126133. doi:10.1590/S0080-62342010000100018

Leal, S. M. C. (2010). Lugares de (não) ver - As representações sociais da violência contra a mulher na Atenção Básica de Saúde (Tese de doutorado em Enfermagem, Universidade Federal do Rio Grande do Sul, Porto Alegre, RS, 
Brasil). Recuperada em http://www.lume.ufrgs. br/bitstream/handle/10183/28043/000768933. pdf? sequence $=1$

Lerner, D. (Dir.). (2009). Kirot (The assassin next door)/Lado a lado com um assassino [Filme]. EUA; Israel; França. Cor. 103 min. Legendado.

Lilienfeld, J. P. (Dir.). (2012). Arretez moi/Prenda-me [Filme]. França. Cor. 99 min. Legendado.

Lima, V. L., \& Silva, A. F. (2012). Conhecendo o perfil e os sentimentos das mulheres vítimas de violência atendidas na Delegacia Especializada de Atendimento à Mulher do município de Belém. Gênero na Amazônia, 2, 111-123. Recuperado em http://www.generonaamazonia.ufpa.br/ edicoes/edicao-2/Artigos/Conhecendo $\% 20$ o\%20Perfil\%20e\%20os\%20Sentimentos\%20 de $\% 20$ Mulheres\%20V\%C3\%ADtimas\%20 de $\% 20$ Viol $\%$ C3\%AAncia $\% 20$ Atendidas $\% 20$ na $\% 20$ Delegacia $\% 20$ Especializada $\% 20 \mathrm{de} \% 20$ Atendimento $\% 20 \% \mathrm{C} 3 \% \mathrm{~A} 0 \% 20 \mathrm{Mulher} \% 20$ do $\% 20$ Munic \% C3\%ADpio $\% 20$ de $\% 20$ Bel\%C3\%A9m.pdf

Lima, G. Q., \& Werlang, B. S. G. (2011). Mulheres que sofrem violência doméstica: Contribuições da psicanálise. Psicologia em Estudo, 16(4), 511520. doi:10.1590/S1413-73722011000400002

Lurie, R. (Dir.). (2011). Strow Dogs/Sob o domínio do medo [Filme]. Estados Unidos. Cor. $110 \mathrm{~min}$. Legendado.

Madureira, A. B., Raimondo, M. L., Ferraz, M. I. R., Marcovicz, G. V., Labronici, L. M., \& Mantovani, M. F. (2014). Perfil de homens autores de violência contra mulheres detidos em flagrante: Contribuições para o enfrentamento. Escola Anna Nery Revista de Enfermagem, 18(4), 600606. doi:10.5935/1414-8145.20140085

Martino, M. (Dir.). (2006). Mulheres do Brasil [Filme]. Brasil. Cor. 106 min.

Mesquita, A. P. (2010). As Marias que não calam: Perfil das mulheres vítimas de violência após a implementação da lei Maria da Penha em Maceió/AL. Recuperado em http://www.fazendogenero.ufsc.br/9/resources/anais/1278269236 ARQUIVO_Texto_Competo_asmariasFG9.pdf

Monteiro, F. S. (2012). O papel do psicólogo no atendimento às vítimas e autores de violência doméstica. Brasília, DF. Recuperado em http://repositorio.uniceub.br/bitstream/123456789/2593/3/20820746.pdf
Moreira, J. O., Romagnoli, R. C., \& Neves, E. O. (2007). O surgimento da clínica psicológica: $\mathrm{Da}$ prática curativa aos dispositivos de promoção da saúde. Psicologia: Ciência e Profissão, 27(4), 608-621. doi:10.1590/S141498932007000400004

Mundhra, J. (Dir.). (2006). Provoked/Desejo de liberdade [Filme]. Reino Unido, Índia. Cor. $113 \mathrm{~min}$. Legendado.

Nava, G. (Dir.). (2006). Bordertown/Cidade do silêncio [Filme]. EUA. Cor. 100 min. Legendado.

Paim, I. A., Filho. (2010). Compulsão à repetição: Pulsão de morte "trans-in-vestida" de libido. Revista Brasileira de Psicanálise, 44(3), 117126. Recuperado em http://pepsic.bvsalud. org/scielo.php?script=sci_arttext\&pid=S0486$-641 \mathrm{X} 2010000300012$

Paiva, A. C. R., Santos, V. R. P., \& Santos, S. M. (2014). Violência doméstica e as implicações na saúde fisica e emocional de mulheres: Inferências de enfermagem. Trabalho apresentado no SEGET: XI Simpósio de Excelência em Gestão e Tecnologia. Recuperado em http://www.aedb. br/seget/arquivos/artigos14/23020192.pdf

Pinheiro, R. K. (2012). O cinema e a violência contra mulher. O discurso de autoria feminina/masculina em três produções Hollywoodianas. Recuperado em http://www.abrapui.org/anais/ComunicacoesCoordenadasLingua/22.pdf

Pimentel, A. (2011). Violência psicológica nas relações conjugais: Pesquisa e intervenção clínica. São Paulo, SP: Summus.

Política Nacional de Enfrentamento à Violência contra as Mulheres. (2011). Brasília, DF: Presidência da República, Secretaria de Políticas para as Mulheres. Recuperado em http://www.spm.gov. br/sobre/publicacoes/publicacoes/2011/politica-nacional

Portella, M., Cortez, M., \& Carpigiani, P. (2011). Os primeiros passos do psicoterapeuta. In B. Carpigiani (Ed.), Teorias e técnicas de atendimento em consultório de Psicologia (pp. 269-281). São Paulo, SP: Vetor.

Santeiro, T. V. (2013). Cinema e realidades na formação em Psicologia Clínica: Proposições teóricas. In T. V. Santeiro \& D. R. Barbosa (Eds.), A vida não é filme? Reflexões sobre Psicologia e Cine$m a$ (pp. 175-202). Uberlândia, MG: Editora da Universidade Federal de Uberlândia. 
Santeiro, T. V., \& Rossato, L. (2013). Cinema e abuso sexual na infância e adolescência: Contribuições à formação do psicólogo clínico. Psicologia: Teoria e Prática, 15(3), 83-94. Recuperado em http://pepsic.bvsalud.org/scielo.php?script=sci arttext\&pid=S1516-36872013000300006\&lng= pt\&nrm=iso

Santeiro, T. V., Rossato, L., Juiz, A. P. M., \& Gobbetti, G. J. (2014). Psicodinâmica das relações incestuosas: Assassinato e renascimento da alma em Preciosa. Psicologia em Estudo, 19(1), 93102. doi:10.1590/1413-7372189590009

Santos, M. A., \& Vieira, E. M. (2011). Recursos sociais para apoio as mulheres em situação de violência em Ribeirão Preto, SP, na perspectiva de informantes-chave. Interface Comunicação Saúde Educação, 15(36), 93-108. doi:10.1590/ S1414-32832011000100008

Silva, C. D., Gomes, V. L. O., Acosta, D. F., Barlem, E. L. D., \& Fonseca, A. D. (2013). Epidemiologia da violência contra a mulher: Características do agressor e do ato violento. Revista de Enfermagem da UFPE online, 7(1), 8-14. doi:10.5205/ reuol.3049-24704-1-LE.0701201302
Strasburger, V. C., Wilson, B. J., \& Jordan, A. B. (2011). Crianças, adolescentes e a mídia (2. ed.). Porto Alegre, RS: Penso.

Vieira, M. A. (2013). A violência do trauma e seu sujeito. In O. M. R. Machado \& E. Derezensky (Eds.), A violência: Sintoma social da época (pp.73-89). Belo Horizonte, MG: Scriptum Livros.

Waiselfisz, J. J. (2015). Mapa da violência 2015: A cor dos homicídios no Brasil. Rio de Janeiro, RJ: Flacso.

Werneck, S. (Dir.). (2009). Sonhos roubados [Filme]. Brasil. Cor. 85 min. 